\title{
Os limites do semi-simbolismo na arte abstrata
}

\author{
Camila dos Santos RIBEIRO (Universidade de São Paulo)
}

RESUMO: Isolados nos primeiros momentos da semiótica, os domínios do plano de expressão passam a ser explorados por meio do conceito de semi-simbolismo. Contudo, nem todos os efeitos de sentido próprios desse plano podem ser descritos assim. Nosso trabalho vai ao encontro da exploração desses limites no estudo da arte abstrata.

PALAVRAS-CHAVE: semiótica; semi-simbolismo; plano de expressão; pintura

ABSTRACT: At first excluded in the semiotics studies, the expression of a text is explored by the concept of semi-symbolism. However, not all the effects of meaning derived from this plane can be described using the semi-symbolic analysis. Our work explores this limitations in the study of abstract art.

KEYWORDS: semiotics; semi-symbolism; expression; painting. 


\section{Introdução}

Como se já não bastasse o notório deslocamento do objeto artístico na situação moderna, a arte abstrata parece sofrer ainda mais especulações acerca de seu estatuto estético. Muitos julgam-na como arte ornamental, outros - paradoxalmente - acreditamna ora como sem significação alguma, ora como apta a múltiplas interpretações.

Recorrendo à teoria da arte para uma análise mais confiável e menos tendenciosa, frustramo-nos ainda mais: o que quase sempre encontramos são ou um panorama do contexto histórico da produção da obra em questão, uma biografia do artista que a produziu ou ainda uma mera descrição do que se vê (seus materiais, composição etc.).

Desse modo, a obra de arte é justificada, ou interpretada, pelo seu entorno e não por ela mesma. Quando a obra a ser analisada é de natureza abstrata, encontramos ainda menos método no modo de abordagem: fala-se em livre interpretação; julgam-na sem significado; tenta-se impingir figuras onde não há; classificam-na como de fácil confecção e pouca estética - etiquetam-na como mero ornamento.

Diante disso, pensamos que a semiótica greimasiana - sendo uma teoria que busca explicar o processo de significação de um dado texto de maneira imanente e munida de modelo teórico consolidado - faz-se bastante útil para uma análise justa das artes plásticas, principalmente depois do desenvolvimento do conceito de semisimbolismo, o que trouxe à tona a possibilidade do estudo do plano da expressão conjuntamente com o plano do conteúdo.

A questão a ser levantada é se uma análise semi-simbólica - na qual se buscam homologações de categorias do plano do conteúdo com categorias do plano da expressão - seria de fato pertinente ou até mesmo possível em textos plásticos abstratos, nos quais a expressão parece ser o único plano trabalhado. Pretendemos, portanto, discutir os limites do semi-simbolismo em pinturas abstratas e propor outros caminhos para a análise desse tipo de texto, como a idéia da existência da geração de sentido também no plano da expressão (já anunciada por L. Hjelmslev em Prolegômenos a uma teoria da linguagem a partir da noção de isomorfia dos planos) e alguns encaminhamentos para a sistematização de uma enunciação plástica.

\section{A semiótica e a expressão omitida}

O que a teoria semiótica (de linha francesa) procura, mais do que explicar os sentidos de dado texto, é explicitar seu processo de significação. Mesmo sabendo que um sistema semiótico se dá pela relação entre um plano de conteúdo e um plano de expressão, A. J. Greimas em uma primeira instância os dissocia e constrói um modelo teórico para dar conta apenas do plano do conteúdo, deixando as possíveis articulações deste com o plano da expressão para o que ele mais tarde chamou de "semiótica do futuro" (Greimas, 1986:56) 
A preocupação de Greimas, de início, é descrever o que L. Hjelmslev conceitua como forma do conteúdo. Para isso, propõe-nos um simulacro metodológico chamado "percurso gerativo do sentido" - uma solução vertical encontrada para sistematizar o processo de significação. Além da clara alusão terminológica (e apenas isso) às teorias de N. Chomsky, o percurso é chamado de gerativo porque mostra como o sentido é gerado a partir de estruturas simples e abstratas as quais vão ganhando complexidade e concretude conforme são enriquecidas em níveis mais superficiais.

O nível de aparência mais concreta é o chamado discursivo, o qual, ainda fazendo parte do plano do conteúdo, carece de manifestação no plano da expressão. A expressão pode ser de natureza verbal (como na literatura), não-verbal (pintura, escultura, música etc.) ou sincrética - em que há a concomitância tanto de elementos verbais como não-verbais (como nas histórias em quadrinhos ou no cinema não-mudo).

Como já dito, Greimas, em um primeiro momento, exclui o estudo do plano da expressão de seu modelo teórico. Segundo L. Tatit (FIORIN: 2003, p. 206) :

"(...) podemos dizer que a semiótica dissocia o plano do conteúdo do plano da expressão e estuda-os separadamente até reunir condições conceituais para relacionar categorias de ambos os planos e então compreender melhor o mecanismo geral da semiose."

Apesar de L. Tatit afirmar que a semiótica dissociou os dois planos e os estudou separadamente, temos de lembrar que um estudo isolado do plano da expressão nunca foi de fato uma realidade. Ao contrário, o que assistimos foi sempre a um reinado absoluto dos estudos do plano do conteúdo enquanto o plano da expressão constava como um problema a ser resolvido.

Há, porém, nas palavras de Tatit já uma pista do que ocorrerá com o plano da expressão - esse tomará lugar nos estudos semióticos quando se conseguir relacionar as categorias dos dois planos. Pietroforte (2004 : 8) nos diz o seguinte:

"Colocado de lado em um primeiro momento do desenvolvimento teórico da semiótica, o plano da expressão passa a ser tomado como objeto de estudo quando uma categoria do significante se relaciona com uma categoria do significado, ou seja, quando há uma relação entre uma forma da expressão e uma forma do conteúdo."

Ou seja, essa homologação entre uma forma da expressão e uma forma do conteúdo nada mais é do que o conceito de semi-simbolismo. E foi só a partir do desenvolvimento deste que o estudo do plano da expressão pôde finalmente emergir na teoria semiótica francesa. 


\section{Jean-Marie Floch e o semi-simbolismo: a expressão considerada}

Como já mencionado, o semi-simbolismo se dá quando da possibilidade da homologação de categorias do plano do conteúdo com categorias do plano da expressão. Podemos dizer que essa relação é, ao mesmo tempo que motivada (já que relaciona diretamente categorias dos dois planos), arbitrária, pois só se dá em um contexto específico. Destarte, citando novamente Pietroforte (2004 : 8-9):

"(...) partindo dos conceitos de signo e de símbolo de F. de Saussure, define-se o semi-simbolismo entre o arbitrário de signo e o motivado do símbolo."

O maior expoente no desenvolvimento do conceito de semi-simbolismo e da chamada semiótica visual (ou plástica) é o francês Jean-Marie Floch. Focando seus estudos principalmente nos textos de comunicação e marketing, além de alguns trabalhos relacionados às artes plásticas, ao gosto e ainda algumas análises de textos fotográficos e de histórias em quadrinhos, Floch conseguiu desenvolver bastante o modelo de análise semi-simbólica nos textos visuais/plásticos e sincréticos, além de trazer finalmente à tona - mesmo que associado ao plano do conteúdo - o plano da expressão para a teoria semiótica.

Basicamente o que Floch propõe é a existência de categorias do plano da expressão - as categorias eidéticas, cromáticas e topológicas (concernentes à forma, às cores e à organização espacial, respectivamente) - as quais seriam análogas a categorias do plano do conteúdo (tais como vida vs. morte, natureza vs. cultura, identidade $v s$. alteridade etc.), ou seja, o conceito clássico de semi-simbolismo: categorias homólogas nos dois planos da linguagem.

Exemplificando, poderíamos ter um quadro em que (no plano da expressão) as cores quentes, os elementos retilíneos e o espaço central se homologassem ao conteúdo "morte" enquanto que as cores frias, os elementos curvilíneos e o espaço periférico se relacionassem à "vida" no plano do conteúdo. Assim, a categoria fundamental desse quadro, em plano do conteúdo, seria vida $v s$. morte e no plano da expressão a oposição seria entre quente/retilíneo/central e frio/curvilíneo/periférico.

A proposta semi-simbólica de Floch parece funcionar muito bem para textos sincréticos em que há o envolvimento de uma expressão verbal, por exemplo, peças publicitárias e histórias em quadrinhos, além de se mostrar bastante produtiva para a análise de fotografias e de pinturas figurativas. Os problemas, porém, começam a aparecer quando saímos desses textos mais híbridos ou ricos em figuras, para adentrar textos mais abstratos, em que a expressão parece ser o único plano pertinente e não temos mais o que R. Barthes (1984:32-33) chama de "ancoragem", tal como títulos e legendas.

Ou seja, enquanto temos um texto sincrético (envolvendo uma manifestação verbal), identificar a categoria fundamental do plano do conteúdo se torna bem menos 
ardiloso - isso porque temos um texto verbal contribuindo para a formação daquele conteúdo e, como sabemos, para o estudo de textos verbais a semiótica possui um método de análise já bastante desenvolvido. Além disso, para ajudar na homologação da oposição fundamental do plano do conteúdo com as categorias do plano da expressão, uma história em quadrinhos (texto sincrético), por exemplo, é bastante rica em figuras, as quais percebemos orbitar (talvez até por sua aparente concretude advinda de sua proveniência discursiva) ora como elementos do conteúdo, ora como elementos da expressão. Por exemplo, a figura de um patrão gordo intransigente se associa à categoria /curvilíneo/ no plano da expressão. Assim, /curvilíneo/ pode ser homologado ao termo simples /opressão/ (patrão) no plano do conteúdo, e aí identificamos um semi-simbolismo.

Em textos plásticos puramente figurativos, a identificação do semi-simbolismo também se faz de modo mais ou menos simples pois, como já explicado, as figuras costumam fundir plano do conteúdo e plano da expressão - enquanto já prevista no modelo do percurso gerativo do sentido, a figura se identifica como integrante do plano do conteúdo. Quando expressa em um texto plástico, no entanto, ela imediatamente perde sua "pseudo-abstraticidade" para ganhar elementos expressivos, tais como cor e forma. Daí a rápida identificação das categorias de expressão dessa figura com as do plano do conteúdo.

No entanto, cabe-nos questionar se de fato há textos não-verbais puros. Geralmente, uma obra de arte - seja ela uma pintura, desenho, instalação, escultura, fotografia etc. - vem acompanhada de um título; um perfume (além de seu frasco) acompanhado de nome e propaganda; uma fotografia não-artística (jornalística, por exemplo), acompanhada de legenda. Assim, tendo a noção semiótica de texto como um "todo de significação", acreditamos poder considerar tais elementos, antes tidos como secundários, como constitutivos desses textos (e não apenas uma ancoragem, como propõe R. Barthes) haja vista a contribuição daqueles em sua significação. Destarte, reunindo o não-verbal da pintura, fotografia, perfume etc. com o verbal do título/nome/legenda chegaríamos à conclusão de se tratarem não mais de textos puramente não-verbais, mas de textos sincréticos

No que concerne à análise de textos artísticos, Floch realizou alguns estudos bastante interessantes, como a análise do $N u$, de Boubat, uma fotografia, e a de uma pintura de Wassily Kandinsky intitulada Composição IV (1911). Sobre o $N u$ não há muito o que se explorar pois tratava-se de um texto fotográfico figurativo. O que nos interessa, porém, foi esse último estudo citado, o da Composição IV de Kandinsky.

Geralmente classifica-se esse estudo como a análise de uma pintura abstrata. E, considerando-a assim, a análise semi-simbólica atingida por Floch seria de uma genialidade e originalidade indiscutíveis. Devemos ressaltar, porém, a ingenuidade da classificação de tal pintura como abstrata quando de um olhar atento a sua constituição.

www.fflch.usp.br/dl/semiotica/es 
Quando pensamos em oposições tais como figurativo vs. abstrato, devemos considerar - sob um olhar semiótico - sempre suas negações como integrantes de um paradigma o qual pode ser lançado no quadrado semiótico. Assim, chegamos à conclusão de haver, pelo menos, quatro tipos de representação plástica : a figurativa e a abstrata bem como a não-figurativa e a não-abstrata.

Observando diversas pinturas, chegamos a algumas definições do que seria cada um desses tipos de representação, são elas:

- Figurativa: seu espaço abarca uma representação referencial de objetos/cenas do mundo, geralmente acompanhada de um título reiterativo das figuras/cenas representadas;

- Não-Figurativa: o objeto/cena do mundo é simplificado e quase esvaziado semanticamente de forma a caminhar para uma abstração, seu título ainda conserva função referencial;

- Abstrata: seu espaço não indica referentes no mundo e sua constituição é essencialmente de formas expressivas tais como linhas e manchas. Seu título geralmente descreve uma expressão e não um conteúdo;

- Não-abstrata: a representação absolutamente abstrata recebe conteúdo referencial a partir de seu título, que passa a se referir não mais às formas pintadas mas a um objeto/cena do mundo.

Com praticamente toda segurança podemos afirmar que, pelo menos os pintores ditos abstratos, em algum momento de suas carreiras, passaram por todos esses tipos de representação. O artista holandês Piet Mondrian é um exemplo disso. No começo de sua produção artística (por volta de 1899 a 1910), Mondrian pintava telas basicamente figurativas como Árvores sobre o Gein ao Luar (1907). A partir de 1911, mais ou menos, Mondrian produz telas por nós identificadas como não-figurativas, é o caso de Árvores em Flor, de 1912. E é por volta de 1920 que Mondrian começa a pintar suas telas características - as séries de grades de linhas negras preenchidas por cores em sua maioria primárias, por exemplo Composição com vermelho, amarelo $e$ azul (1924). Mondrian, porém, não encerra sua carreira na representação abstrata, suas últimas telas (a partir de 1940) enquadram-se naquilo que classificamos como representação não-abstrata, ou seja, dá-se um título com um referencial no mundo para uma representação sem referentes - abstrata - é o caso da tela Broadway BoogieWoogie, de 1943.

Desse modo, podemos esboçar um quadrado semiótico das formas de representação possíveis:

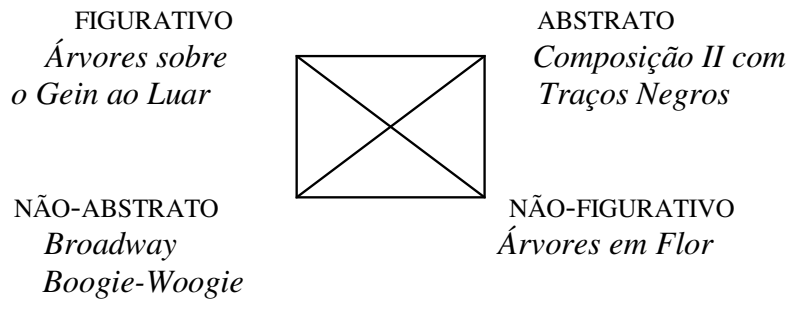

www.fflch.usp.br/dl/semiotica/es 
Após esse esboço de uma tipologia dos modos de representação plástica, podemos retornar ao caso da análise de Floch do quadro Composição IV de Kandinsky. Ao observar a tela em questão concluímos tratar-se não de uma obra abstrata (segundo nossa sistematização) e sim de uma obra não-figurativa. Desse modo, entende-se a pertinência e a produtividade de uma análise semi-simbólica para Composição IV. Isso porque, apesar de conter indício de abstração, a tela ainda conserva figuras, as quais podem ser bastante simplificadas mas ainda referentes a objetos/cenas do mundo. Assim, possibilita-se a homologação das categorias do plano do conteúdo com as do plano da expressão de modo relativamente simples.

A pergunta a ser levantada é como se daria o semi-simbolismo em uma pintura abstrata, a qual não possui vestígio de figuras e, na maioria das vezes, é acompanhada de título que descreve suas características plásticas e formais, tal como "Composição com vermelho, amarelo e azul", tela de Mondrian de 1924.

\section{Hjelmslev e a expressão por si mesma}

Em uma tela abstrata parece-nos difícil aceitar que manchas de tinta preta poderiam de imediato se corresponder com uma categoria do tipo /liberdade/ $v s$. /opressão/ em uma tela de Jackson Pollock, já que não teríamos qualquer apoio mais concreto para isso (como figuras ou ancoragens verbais); ou ainda que linhas perpendiculares se homologariam ao elemento "vida" enquanto linhas paralelas seriam correspondentes à "morte", em uma composição de Piet Mondrian. O que nos leva a pensar na improdutividade e até mesmo na não-pertinência de uma análise semisimbólica para esse tipo de pintura. Postular, porém, que um quadro abstrato não possua conteúdo é condená-lo ao rótulo de mero ornamento e bani-lo do estatuto de arte. Desse modo, resta-nos a conclusão de que se há sentido em uma pintura abstrata, esse deve estar em seu plano da expressão.

Pensamos, portanto, que, ao mesmo tempo em que se deve investigar o funcionamento do semi-simbolismo na arte abstrata, não se pode deixar de lado algo anunciado por L. Hjelmslev em seu Prolegômenos a uma teoria da linguagem (2003: 60-61) - e , parece-nos, até hoje ignorado - como sendo o "sentido da expressão":

"Sendo manifestamente a mesma a situação para a expressão e seu conteúdo, convém ressaltar este paralelismo pelo uso de uma mesma terminologia para a expressão e para o conteúdo. Seria possível assim falar de um sentido da expressão, e nada impede de fazê-lo, embora isso seja algo contrário ao habitual. (...) Isto nos mostra que as duas grandezas que contraem a função semiótica, a expressão e o conteúdo, comportam-se de modo homogêneo em relação a ela (...)" 
Ou seja, Hjelmslev nos sugere que do mesmo modo em que há sentido sendo gerado no plano do conteúdo, deve haver também sentido gerado no plano da expressão, visto que os dois planos da linguagem são homogêneos e isomorfos. Admitindo-se, portanto, a existência de um sentido da expressão, admite-se também a necessidade de, aos moldes do que ocorreu no plano do conteúdo, o desenvolvimento de um modelo de análise que dê conta desse sentido gerado em expressão.

Em nível discursivo, o que estamos investigando com grandes avanços são os modos de enunciação, ou seja, tipos de enunciação plástica.

\section{Preliminares a uma tipologia de enunciação plástica}

Heinrich Wölfflin, historiador de arte, em seu livro Conceitos fundamentais da história da arte, afirma a existência no tempo de dois tipos básicos de representação: um, anterior, o linear e outro, posterior, o pictórico. A representação linear caracterizase por linhas e contornos enquanto que a pictórica por manchas e agrupamento.

"Portanto, podemos estabelecer assim a diferença entre os dois estilos: a visão linear distingue nitidamente uma forma de outra, enquanto a visão pictórica, ao contrário, busca aquele movimento que ultrapassa o conjunto dos objetos. No primeiro caso, linhas regulares, claras, delimitadoras; no segundo, contornos não acentuados que favorecem a ligação." (Wölfflin, 2000: 27)

Mais adiante Wölfflin descreve o estilo linear como produtor de efeito de objetividade, enquanto que o estilo pictórico produziria efeito de subjetividade. Nesse momento, já podemos ter pistas de como semiotizar tais estilos e de onde enquadrá-los: na enunciação plástica.

Pensando na encunciação discursiva do plano do conteúdo podemos resumi-la a dois tipos básicos: a enunciva e a enunciativa. Na enunciação enunciva o enunciador se descola/afasta do enunciado, produzindo o efeito de objetividade - estamos aí na pessoa do ele, no tempo do então e no espaço do lá. A enunciação enunciativa, por sua vez, caracteriza-se por um enunciador colado/marcado na enunciado e produz o efeito de comprometimento e subjetividade - a pessoa é o eu/tu, o tempo é do agora e o espaço é do aqui.

Ora, pensando plasticamente, se fôssemos identificar uma enunciação plástica enunciva e uma enunciativa, seguindo a teoria de Wölfflin, chegaríamos à conclusão de que o estilo linear, por sua objetividade, corresponderia a uma enunciação plástica enunciva, enquanto que o estilo pictórico, por sua subjetividade, corresponderia à enunciação plástica enunciativa.

Essa relação, porém, não é tão frouxa quanto parece. Quando de uma enunciação linear o que temos são linhas e contornos bem definidos, ou seja, delimitação de áreas e consequentemente, afastamento plástico. Já na enunciação 
pictórica, por se caracterizar pelas manchas e ausência de contornos e limitações, há uma aproximação plástica dos elementos. Desse modo, chegaríamos não mais à oposição objetivo vs. subjetivo, mas também à oposição afastamento vs. aproximação do enunciador, ou seja, mais uma identificação com as categorias da enunciação em plano de conteúdo.

Tendo os dois tipos básicos de enunciação (linear/enunciva $v s$. pictórica/enunciativa) sistematizados, resta-nos identificar o processo de actorialização, espacialização e temporalização no texto plástico. Acreditamos que um modo de marca de pessoa em um texto plástico se caracterizaria pelo que Omar Calabrese (Calabrese,1987:37) chama de "a mão do pintor", ou seja, a própria pincelada deferida sobre a tela. Isso nos parece bastante plausível se olharmos para pinturas como LouisFrançois Bertin (1833), de J-A-D Ingres, em que qualquer marca de pincelada é apagada, produzindo um efeito praticamente de fotografia, em contraposição ao, Émilie Ambre no papel de Carmem (1880), de Edouard Manet em que a pincelada é nítida e remete ao sujeito o tempo todo. Ainda não temos certeza se a "mão do pintor" é de fato um processo de actorialização ou se não é também apenas uma pista do tipo de enunciação (enunciva/enunciativa), marcando não o sujeito enunciado, mas o sujeito enunciador.

Já sabemos, porém, que esse tipo de identificação da enunciação plástica é possível de forma relativamente óbvia também na pintura abstrata. Para dar um exemplo bastante didático de como seria uma enunciação enunciva e enunciativa nesse tipo de pintura podemos pensar basicamente em dois pintores: um, já citado, Mondrian e o outro, Jackson Pollock, artista norte americano de nascimento posterior a Mondrian porém de produção a ele contemporânea. Dizemos que a identificação é bastante óbvia pois, se enunciação linear caracteriza-se por linhas e a pictórica por manchas, há exatamente esses elementos radicalizados nesses dois pintores: o primeiro é conhecido por suas grades de linhas pretas as quais delimitam as cores, enquanto o segundo, pela técnica de dripping (gotejamento), imprime manchas em suas telas. Assim, concluímos que Mondrian produz telas por meio de enunciação enunciva, enquanto Pollock o faz por meio de enunciação enunciativa. A marca da "mão do pintor" também aprece bem definida nesses dois pintores: em Mondrian ela é apagada, enquanto que em Pollock ela explode em todo o espaço pintado.

\section{REFERÊNCIAS BIBLIOGRÁFICAS}

CALABRESE, O. "Problémes d'enonciation abstracte", in: Actes Semiotiques, 1987

FLOCH, J.-M., Petites mythologies de l'œil et de l'esprit - pour une sémiotique plastique. Paris: Hades-Benjamins, 1995

FIORIN, J.L., (org.), Introdução à Lingüística - objetos teóricos. São Paulo: Contexto, 2002

GREIMAS, A.J. “Conversation”, in: Versus, 43, 1986 
HJELMSLEV, L. Prolegômenos a uma teoria da linguagem. São Paulo: Perspectiva, 1975

PIETROFORTE, A.V., Semiótica Visual - os percursos do olhar. São Paulo: Contexto, 2004

WÖLFFLIN, H, Conceitos fundamentais da história da arte. São Paulo: Martins Fontes, 2000 


\section{ANEXO}

\section{Figurativização, abstração e suas negações}

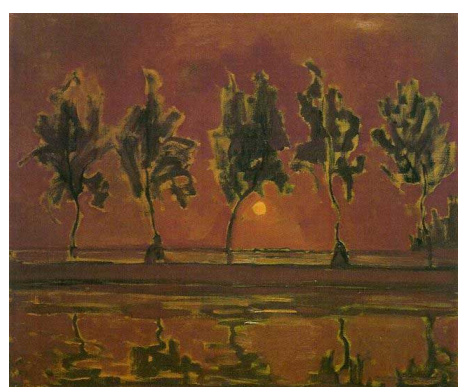

1. Árvores sobre o Gein ao luar Piet Mondrian (1907)

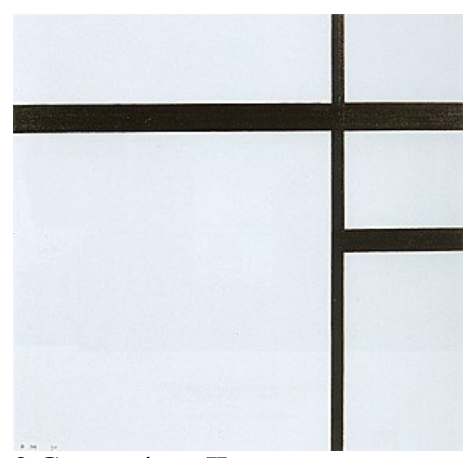

3.Composição II com traços negros Piet Mondrian (1924)

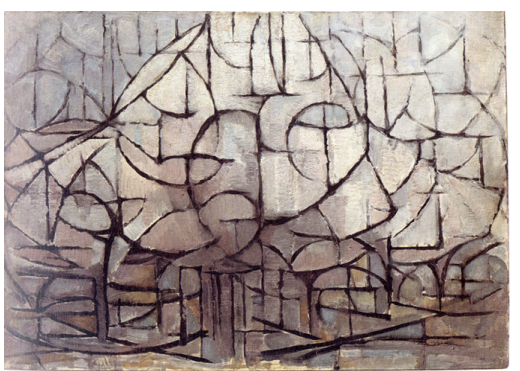

2. Árvores em flor

Piet Mondrian (1912)

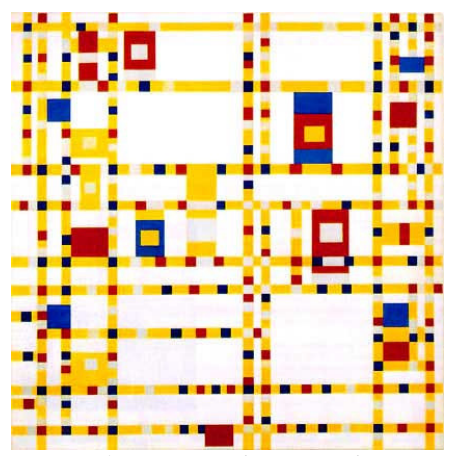

4.Broadway Boogie-Woogie

Piet Mondrian (1943) 


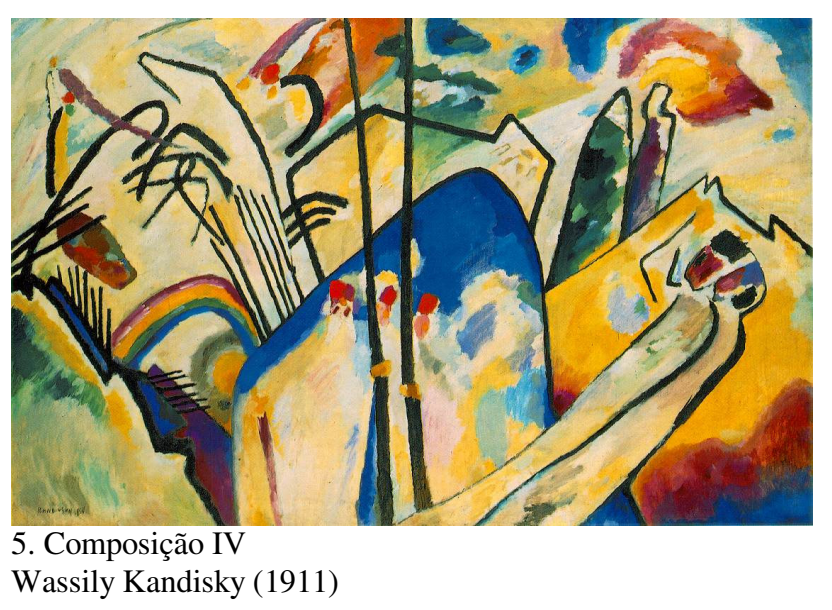

\section{Enunciação linear e pictórica figurativa}

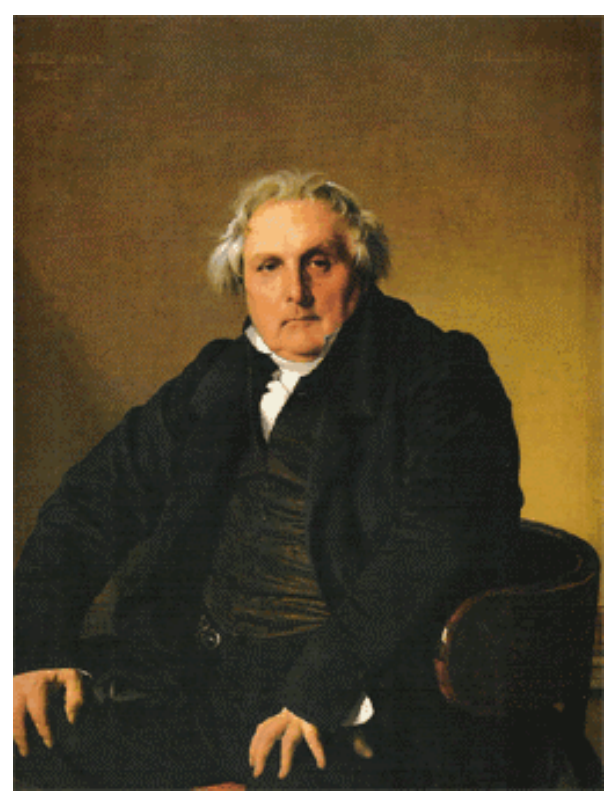

6.Louis-François Bertin

J-A-D Ingres (1833)

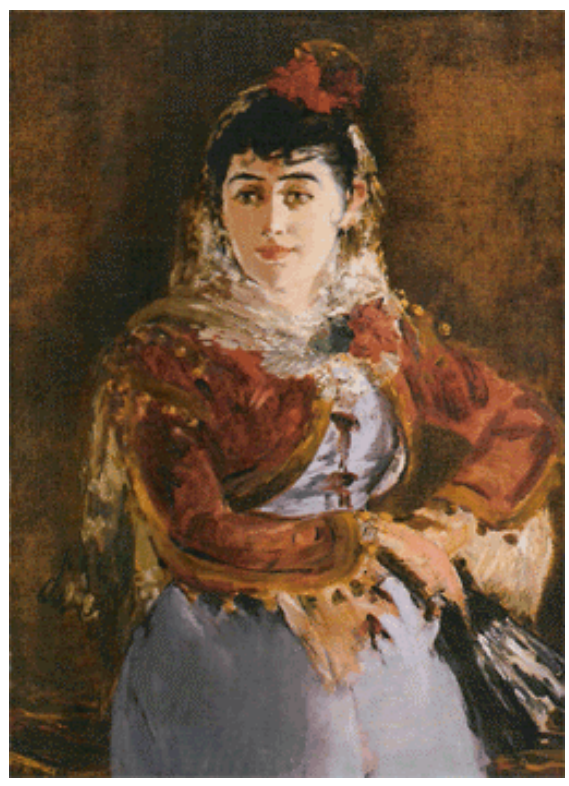

7.Émilie Ambre no papel de Carmem Edouard Manet (1880) 


\section{Enunciação linear e pictórica abstrata}

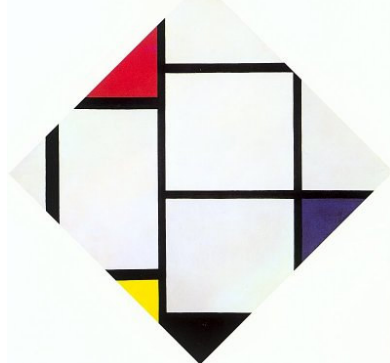

8.Composição com vermelho, amarelo e azul

Piet Mondrian (1924)

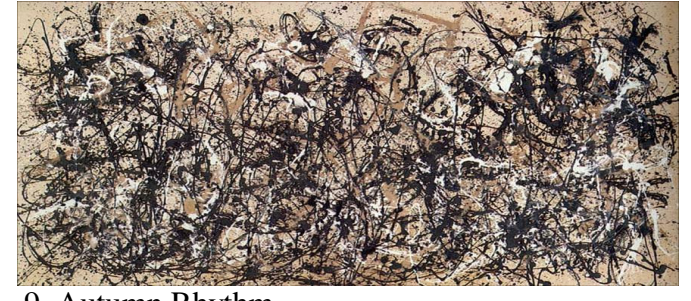

9. Autumn Rhythm

Jackson Pollock (1950)

\section{Como citar este artigo:}

RIBEIRO, Camila dos Santos. Os limites do semi-simbolismo na arte abstrata. Estudos Semióticos, Número 2, São Paulo, 2006. Disponível em $<$ www.fflch.usp.br/dl/semiotica/es>. Acesso em "dia/mês/ano". 